\title{
A Case Study of Teacher Trainee Perceptions on Mixed Peer Review Formats in an Academic Writing Course
}

\author{
Todd Jobbitt* \\ Graduate School of Education, Hankuk University of Foreign Studies, Korea \\ *Corresponding Authors: Todd Jobbitt, Graduate School of Education, Hankuk University of Foreign \\ Studies, Korea

\begin{abstract}
Peer review (PR) in academic writing classes (AWCs) has been shown to have a positive impact on graduate students' writing ability, even for those with limited English L2 writing experience. Such limited exposure to PR may lead to feelings of anxiety and confusion about the process and application in future teaching contexts. This study reports how the use of varying PR formats by a novice teacher-trainee in a graduate-level $(A W C)$ impacted her perceptions of peer review. Students performed two rounds of peer review in two formats, one face-to-face and the second a blind-review, and then answered reflective journal questions after each round. Overall, results show that student found these PR formats as positive and helpful to their writing improvement, but that in their future teaching contexts peer review implementation may require much practice for success.
\end{abstract}

Keywords: peer review circles, academic writing, reflection, reflective practice

Acknowledgements: This work was supported by Hankuk University of Foreign Studies Research Fund of 2020

\section{INTRODUCTION\& LITERATURE REVIEW}

Osterman and Kottkamp's (1993) summative statement, "Learning...is most effective when the learner is actively involved in the learning process, when it takes place as a collaborative rather than an isolated activity, and when it takes place in a context relevant to the learner" (Ch. 2, p. 3) has lost none of its luster nigh on 30 years later. This observation is all the more relevant when applied to inclass learning processes like peer review (also named peer response or peer editing) in an academic writing course (AWC). However, as much as a teacher may want to give the greatest amount of feedback possible, Baker (2016) astutely notes that doing so can be both difficult and time-intensive. To counter these challenges, student peer review is seen as a useful process to not only lessen teacher duties, but to improve students' ability to effectively assess a peers' writing while giving them access to peers' writing. This is done by exposing them to peer drafts, even though there may be limitations to the type (more local than global) of feedback that students may give (Pham \&Ngyuen, 2014) and the edict that to be effective they must follow very clear implementation procedures (Rollinson, 2005).

In order to gain the most benefit from such in-class practices, a secondary learning component needs to be applied - that of reflective practice. Schon (in Ferraro, 2000) defines reflective practice as "thoughtfully considering one's own experiences in applying knowledge to practice while being coached by professionals in the discipline" (p. 2). Indeed, by reflecting on one's own experiences, greater understanding of both content and context can be gained. If teachers are to develop effectively, especially in teacher training programs, then such reflective practice is a vital necessity, and thusly can help them write and reflect better (Cho \& Cho, 2011, as cited in Min, 2016). Pennington markedly comments on this in relationship to teacher training programs (in Johari, 2017) as follows:

a solid teacher education program will have two central goals: 1) to engender an attitude favorable to continued growth and change, and, 2) to provide the skills necessary for analyzing teaching performance, for valuating new ideas, and for implementing those ideas deems worth of putting into practice as part of the individual's career growth (p. 105). 
These ideas are further matched by $\mathrm{Hu}$ (2005), who asserts on behalf of 'advocates of process approaches' (p. 322) that peer review should be used because of the recursive nature of writing, in addition to the idea that writing is a learning process which can be strongly enabled in an 'environment in which students are acknowledged as writers, encouraged to take risks, and engaged in creating meaning' (Zamel, 1987; 697, as cited in Hu, 2005). It is therefore vital that such reflective practice be applied whenever an opportunity presents itself. Incorporating this teacher belief into my graduate students' thinking was the next step.

\subsection{Conceptual Framework}

Applying reflective practice was decided upon to curb student apprehension to peer feedback at the student level. The idea is simple: ask questions about the experience after it has taken place.In earlier research (Jobbitt, 2017), this author, among others (see Baker, 2016) noted that writing students struggled in several ways when approaching and using peer review: they generally fail to initially see the value in peer review, but notice its benefits with repeated usage; they may want all of their grammar corrected, yet do not necessarily see themselves as masters of English toward which to correct others' errors confidently;they tend to rely more so on teacher feedback and so may diminish the value or appropriateness of peer comments. This latter point regarding feedback may impact a student's confidence when participating in peer review. It is quite relevant because the students in this study are teacher-trainees - some novice, some experienced - and they may at some point be teaching academic writing.

The question that arose was how best to approach the idea of applying peer review processes in this AWC that would provide great exposure to peer review formats while using a consistent framework. One solution to this was by designing the course to both maximize writing formats (to include both paragraphs and essays) and peer review applications (face-to-face and anonymous formats). There was a curiosity to try different peer review formats because of wanting these students to have a broader palate of contrastive experiences that they could potentially apply to future teaching contexts.

\section{MeTHOdOLOGY}

\subsection{Participants}

The participants in this Seoul-based university study were three teacher-trainees at a graduate school of education. Students in this program primarily live in or near the Seoul metropolitan area. The class size was 20 students which allowed for peer review to be done in pairs. Students were encouraged by the instructor to find their own partner. The age for all students was roughly in the mid-to-late 20 's, and their teaching experience ranged from novice to limited-experience (mostly private tutoring); none of them had academic writing experience as a teacher. These students were a very homogenous group: all were Korean and female. The instructor was an experienced TESOL instructor trained in teacher training and first-language composition methodology.

\subsection{Limitations of the Study}

There were several challenges to the implementation of peer review in this particular course. First, student experience was a consideration. Although at graduate level, academic writing for this classes' generation was practically nonexistent, this due to the high level of preparation given to Korea SAT tests particularly from Korean middle school through high school, which continues largely to this day (see Jambor, 2009; for a non-writing analysis with a focus on academic content, see Kim, 2020). This intense exam preparation period, coupled with a strong English focus on only speaking and listening, makes for a student population quite devoid of AWC exposure. Second, a 90-minute classroom period is a tightly constrained format for any academic writing class. This contributed to the production of only two drafts (one paragraph and one essay) for each paper type so that a greater variety of process writing could be completed, and also, to hopefully attribute to a stronger sense of completion on the students' behalf. Third, though diligent students, most of these students work full-time jobs, so there was always a bit of uncertainty about how many students would be able to participate in the PR processes. For example, out of a class of 15 students, there were only several students that were able to complete all assignments on time to participate fully in PR processes (feedback and reflections); however, a majority did participate in two of the three peer reviews. Additionally, the 90-minute class time was felt to be an issue. This is a very short time in which to perform peer review, and is one 
reason that pair work was used, versus larger group formats. Shokrpour, Keshavarz and Jafari (2013) state correctly that "feedback is more useful between drafts, and little improvement is made when it is done at the end of the task" (p. 24); with multiple drafts due within a limited amount of time (over several weeks) there was a strong concern about students being able to produce consistent amounts of writing to participate fully in peer review. Finally, a not-overlooked but accepted omission for this study was the lack of both pre- and post-test questionnaires on students' attitudes about peer review, hence the qualitative focus. The reason for not using a questionnaire was simply that student numbers for the class were known to be low (less than 20 students) prior to the course start.

\subsection{Procedure}

Over the course of a 16-week semester, students completedthree different types of process writing paragraphs (narration, process, and compare-contrast). Paragraphs were chosen for feedback processes due to the students' limited-to-none exposure to AWC's in their pre-collegiate academic careers; students needed a clear foundation, this author believed, in basic paragraph fundamentals before progressing to longer, more complicated, essay drafts. Also, the paragraphs were scheduled one week apart early in the semester, to allow suitable time for self-revision and submission of drafts (Hagga, 1993, as cited in Baker, 2016). Final drafts would later be expanded into essays.The students selected for this case study were those who successfully completed all PR sessions and all PR reflection journals.

After each initial paragraph draft was completed, students answered several peer review (PR) reflection questions. As soon as the PR finished, students were given about 5-10 minutes to take notes on their immediate impressions, and they then completed the entire journal at home.Journals were submitted via email or through in-class submission. For each question (see Table 1), a minimum answer of 100 words was requested. The questions were:

Table1. Peer Review Reflective Journal Questions

\begin{tabular}{|l|}
\hline Questions \\
\hline 1. What did you find most helpful about the peer review? (feedback, discussion, etc.) \\
\hline 2. What did you find least helpful about the peer review? (be explicit) \\
\hline 3. What is bothering you most about the peer review? What concerns do you have about the process or what \\
is still unclear about peer review? How could it be made better? \\
\hline 4. Will you implement peer review in your teaching context? Why? Why not? \\
\hline
\end{tabular}

Table 1 shows PR reflection journal questions that the student completed after each peer review session.

There were two different types of peer review (PR), but each format used the same questions sheet (see Appendix A). The first type was a face-to-face format where students answered questions about the draft and then shared their responses to the draft. The second type was a blind format; students were given a classmate's paper 'anonymously' via envelop (see Jobbitt (2015) for more "on this technique". Although PR was completed for all paragraphs and essays, reflections were completed only for and after each paragraph type, not for essays. The reasoning was that increased reflection responses would be redundant and simply too much work for students to complete, given the increased writing demands of essays and other assignments.

A second consideration was the use of the peer review worksheets. The more open format of the question-and-answer worksheet (Appendix A) was very clear to the students, as the peer review had been modeled with sample essays. The use of a grammar checklist was avoided for this study in an effort to not have student focus overtly on local issues (grammar)or error correction (Leki, 1990, as cited in $\mathrm{Yu} \& \mathrm{Hu}, 2017)$.

\section{Results}

Although Sue* (*not her real name) expressed light reservations about PR before trying it, her response was nonetheless very positive. For PR Round 1, question \#1, "What did you find most helpful about the peer review?", she stated:

I got opportunities to develop my ability to give constructive feedback, and received advice on my draft. I liked that I had a broader audience for my work than just a single instructor, and I could see different approaches other students have taken in responding to my writing. 
Discussion with other students was most helpful. It allowed a diversity of opinions to be brought to the table. During the discussion I could interact with them. I could not only get other's feedback but also give them my opinion their feedback.

In her response to this question for PR Round 2, Sue stated that the blind format "would be an effective way for a better peer review" since the paper's author was unknown: "When I knew whose draft it was...I tried not to hurt the writer's feeling. I think it was not an objective feedback. However, when I didn't know who wrote the draft, I felt free to correct something."

This approach may allow for more directness in marking, but also parallels with Lu's (2005) overview on PR that, "the biggest problem with peer review is that students are easily biased or not honest in giving feedback because of friendship, gender, race, interpersonal relationship, or personal likes or dislikes" (p. 6).

For PR Round 1, question \#2, "What did you find least helpful about the peer review?", Sue felt that PR went well, but was less certain about the reflection journals: "Everything that I did class was helpful. However, I don't know how peer review reflection journals help me to improve my writing. I hope that I see the benefits by the end of the course." This sentiment remained in the PR Round 2 blind-format with an implied plea of, "I hope that there will be no more journals." BurhanHoranssanh\&Ortactepe (2016) note that "Reflection-on-action requires teachers to look back on their past experiences and evaluate them by sharing their ideas and perceptions" (p. 375). Perhaps the newness of the reflection process, coupled with its solitary nature - reflection responses were not discussed with peers - accounted for these feelings, both indicating a limitation of the study and the need for stronger reflective processing in future PR research.

For PR Round 1, question \#3, "What is bothering you most about peer review?", Sue expressed concerns about feedback quality and feedback quantity:

I cannot be sure about the quality of the peer review on my writing. How can I know the revision is better when I revise my draft using the feedback from only one student (sic).

This is a common student concern about peer review in this author's experience. Further, Sue's response, which may be indicative of her own perceived ability to give feedback, seems to align with Dijks, Brummer and Kostons' (2018) findings that, "students perceived peer feedback as more adequate when knowing the peer reviewer perceived his or her expertise in giving feedback to be high" (p. 1267). Questioning the quality of others' feedback, or having reservations about such, is not an unusual reaction from students (Zhang, 1995), while other research (Lundstrom \& Baker, 2009) has revealed that students tend to improve more in their own writing than they do from receiving feedback from others. This may be one reason why Sue felt ambivalent about peer feedback.

Another intriguing observation by Sue was here opinion that peer review groupsneeded to be in a larger format, something this author has been experimenting with in AWCs:

Feedback from more than two reviewers will be better, so at least two peer reviewers on one draft are needed. I think groups of three or four for peer review will be better. Also, time constraints may make it impossible to do a good peer review. I need more time for a better peer review.

The social component is seen as a positive side-effect of peer review (Rollinson, 2005; Vokic, 2007) by students, yet this comment may seem a bit incongruous given the following response to PR Round 2 , \#3. In that response, her focus shifted from feedback quality concerns toward a clear reiteration about the before-mentioned time constraints from PR Round 1. Sue responded:

Time constraints may make it impossible to do a good peer review. I need more time on doing actual review. I don't think we should as many things as possible in class. Instead, I want to have more time to review other's draft (sic).

This observation may imply that Sue was beginning to observe more value in the peer review process or that her feedback skills were beginning to develop, at least internally, both of which can be seen as important advances toward her understanding of PR processes.

For PR Round 1, question \#4, "Will you implement peer review in your teaching context? Why? Why not?", Sue noted the potential advantages first, stating: 
There is no doubt that the process is not perfect, (sic) however, I will definitely use peer review in my class. Having students give feedback to one another on their papers can have many advantages. Peer review is a highly effective method to quality students writing (sic). Students will be more involved in a writing process. They can participate in peer review process, as an author and as a reviewer. Peer review can be categorized by the type of activity, so students can learn by doing it.

while for Round 2 this view was repeated; however, she further expressed potential challenges for both students and teachers in future teaching contexts:

But many Korean students do not know how to peer review. I should give them clear directions on peer reviewing. Whole-class workshops can be helpful for developing shared standards about what to focus on in reviewing a draft and what kind of tone to use in delivering feedback. In addition, peer review has to be carefully managed in order for students to take the process seriously. Students need to be skeptical of the value of receiving feedback from other students rather than teachers.

A bit of healthy skepticism is warranted, as students have been shown to respond adversely or negatively to peer review (Morgan, Fuisting \& White, 2014; Rogers \& Feller, 2016; Zhang, 1995), but with proper training and implementation (Lam, 2010; Rollinson, 2005) most of these concerns lessen over repeated exposures. In this author's experience, peer review is seen as effective by the students until is not, and the factors influencing PR are varied. These factors can be: the frequency of the PR (how many per assignment); the partners' or group members' relationship (friends or not); and the noted time constraints contributing to the intensity of PR duties.

\section{DisCUSSION AND CONCLUSION}

Peer review can yield very different results for each individual class in which it is used. Students react differently to sharing their writing, may fret over which audience to whom they are writing, and might simply not be very interested in either the writing process or the feedback process of sharing drafts, academic requirements notwithstanding. This can create challenges for instructors, and it is here that experience and flexibility, on the student-and-instructor-side may work best together to ensure a positive outcome for all participants.

When introducing peer review to a class with extremely limited academic English writing experience, the resultant consternation and eventual understanding and acceptance of peer review is made all the more revealing. The student in this study found peer review to be very engaging and helpful to her writing processes, in both formats: face-to-face and blind. More importantly, the PR had a positive impact on her attitude - her ability to share and engage with peers allowed for an increased interest in what directions peer review would take her - both as an academic writing student and as a practicing teacher-trainee. More work can be done in both of these areas by this author. These are steps to take in understanding more about the impact of peer review on both student's perceptions and in their future teaching contexts.

\section{REFERENCES}

[1] Baker, K. M. (2016). Peer review as a strategy for improving students' writing process. Active Learning in Higher Education, 17(3), 179-192.

[2] Burhan-Horasanli, E., \&Ortaçtepe, D. (2016). Reflective practice-oriented online discussions: a study on EFL teachers' reflection-on, in and for-action. Teaching and Teacher Education, 59, 372-382.

[3] Dijks, M. A., Brummer, L., \&Kostons, D.(2018).The anonymous reviewer: the relationship between perceived expertise and the perceptions of peer feedback in higher education, Assessment \& Evaluation in Higher Education,43(8),1258-1271,DOI: 10.1080/02602938.2018.1447645

[4] Ferraro, J. M. (2000). Reflective Practice and Professional Development. ERIC Digest.

[5] Retrieved from: https://files.eric.ed.gov/fulltext/ED449120.pdf

[6] Hu, G. (2005). Using peer review with Chinese ESL student writers. Language Teaching Research, 9, 321-342

[7] Jambor, Z. P. (2009). Favorable Teaching Approaches in the South Korean Secondary Classroom. Online Submission.

[8] Jobbitt, T. (2015) Secret paper: a practical peer review technique. International Journal of Teaching English and Language Learning, 2, 1-11 
A Case Study of Teacher Trainee Perceptions on Mixed Peer Review Formats in an Academic Writing Course

[9] Jobbitt, T. (2017) Implementing peer review effectively in academic writing classes. HUFS Journal, pp. 45-61.

[10] Johari, S. K. (2017). Mirrors for an ESL classroom: using reflective teaching to explore classroom practice and enhance professional growth. The English Teacher, 18.

[11] Kim, Y. (2020). Comparison between South Korean and Finnish education: curricula and oral tasks in textbooks in English education for high schools.(Unpublished master's thesis). University of Helsinki, Finland.

[12] Lam, R. (2010). A peer review training workshop: coaching students to give and evaluate peer feedback. TESL Canada, 27(2)

[13] Lu, R. L. (2005). A comparison of anonymous E-peer review versus identifiable e-peer review on college student writing performance and learning satisfaction. Retrieved October 2, 2007.

[14] Lundstrom, K., \& Baker, W. (2009). To give is better than to receive: The benefits of peer review to the reviewer's own writing. Journal of Second Language Writing, 18(1), 30-43.

[15] Min, H. T. (2016). Effect of teacher modeling and feedback on EFL students' peer review skills in peer review training. Journal of Second Language Writing, 31, 43-57.

[16] Morgan, B., Fuisting, B., \& White, J. (2014). University student attitudes towards peer review in EFL writing: A quantitative study. Language Education in Asia, 5(1), 93-116.

[17] Osterman, K. F. \& Kottkamp, R. B. (1993) Reflective Practice for Educators: Improving Schooling through Professional Development. Sage: Newbury Park, CA

[18] Pham, H. V. P., \& Nguyen, D. T. T. (2014). The effectiveness of peer feedback on graduate academic writing at Ho Chi Minh City Open University. Journal of Science HCMC OU-Social Sciences, 4(2).

[19] Rogers, T., \& Feller, A. (2016). Discouraged by peer excellence: Exposure to exemplary peer performance causes quitting. Psychological science, 27(3), 365-374.

[20] Rollinson, P. (2005). Using peer feedback in the ESL writing class. ELT Journal, 59(1),

[21] Oxford University Press.

[22] Shokrpour, N., Keshavarz, N., \& Jafari, S. M. (2013). The effect of peer review on writing skill of EFL students.

[23] Vokic, G. (2008). Feedback in L2 writing: the students' perspective.

[24] Yu, S., \& Hu, G. (2017). Understanding university students' peer feedback practices in EFL writing: Insights from a case study. Assessing Writing, 33, 25-35.

[25] Zhang, S. (1995). Reexamining the affective advantage of peer feedback in the ESL writing class. Journal of second language writing, 4(3), 209-222.https://doi.org/10.1016/1060-3743(95)90010-1

Appendix A

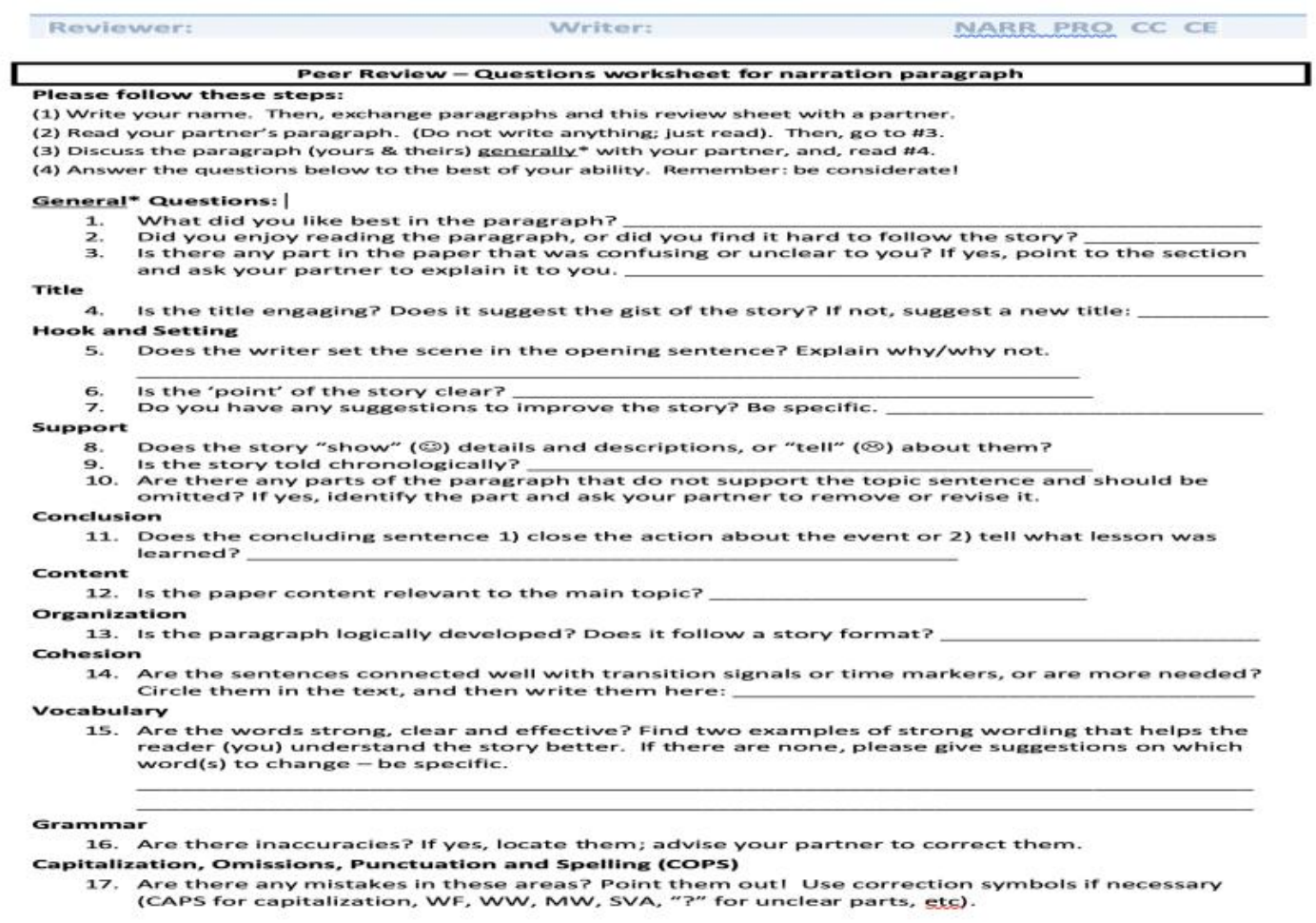



Course

\section{AUTHORS' BIOGRAPHY}

odd Jobbitt works in the Graduate School of Education at Hankuk University of Foreign Studies, Seoul, South Korea. His research interests include academic writing, peer review with Peer Review Circles, extensive reading, and reflective journaling.

Citation: Todd Jobbitt, "A Case Study of Teacher Trainee Perceptions on Mixed Peer Review Formats in an Academic Writing Course” International Journal on Studies in English Language and Literature (IJSELL), vol 8, no. 10, 2020, pp. 11-17. doi: https://doi.org/10.20431/2347-3134.0810002.

Copyright: (C) 2020 Authors. This is an open-access article distributed under the terms of the Creative Commons Attribution License, which permits unrestricted use, distribution, and reproduction in any medium, provided the original author and source are credited. 